\title{
Impact of Line Current Harmonics on the DC Bus Quality of a Three-Phase PWM Inverter
}

\author{
Saeid Haghbin and Torbjörn Thiringer \\ Electric Power Engineering, Chalmers University of Technology, Gothenburg, Sweden \\ Emails: \{saeid.haghbin, torbjorn.thiringer\}@ chalmers.se
}

\begin{abstract}
Three-Phase PWM inverters are widely used in many applications. The de bus of a three-phase PWM inverter is subject of harmonics due to the inherent PWM switching operation that may impose severe consequences to the system. The impact of $5^{\text {th }}$ and $7^{\text {th }}$ harmonic components on the dc bus ripple is investigated in this paper. The analytical formulation and simulation method have been used to quantify the impact of these harmonics on the dc bus quality. The results show that there is a low frequency component with an order of $6\left(6^{\text {th }}\right.$ harmonic $)$ on the inverter dc side current which is explained and discussed here.
\end{abstract}

Index Terms - three-phase PWM inverter, dc bus harmonics, line harmonics, high-frequency model, frequency spectrum

\section{INTRODUCTION}

Three-phase pulse width modulation (PWM) inverters are used in different industrial or commercial applications such as motor drives, uninterruptible power supplies and battery chargers [1]. The dc bus of a three-phase PWM inverter is subject of harmonics due to the inherent switching operation that may impose severe consequences to the system. Especially for a system with multiple devices sharing the same dc bus, harmonics can degrade the performance in terms of high frequency losses, intense transients and noise. Consequently, there are different phenomena of interest that requires a suitable frequency model of the converter towards the dc bus; transient voltages or currents, harmonic depended losses, stability, and electromagnetic compatibility (EMC) issues are typical examples [2], [3]

There are different harmonic elimination or suppression techniques to ease the situation. Typically a large capacitor is used in the dc side to smooth the dc side waveforms. The dc bus capacitor is a heavy and bulky component that can occupy more than $20 \%$ of the inverter volume [4]. Consequently, harmonic analysis in the both ac side and dc side is necessary towards a more effective and cost optimized system.

A three-phase three-wire inverter is a very common configuration in many applications like ac drive systems. The even harmonics and triplen harmonics can't flow in the ac side because of symmetry and zero neutral current.

However, other harmonics like 5th and 7th harmonics can exist in the system for some loads like motors or transformers, especially in saturation operation. It is shown here that those components result a low order harmonic (6th harmonic) plus some higher order harmonics around switching frequency or its multiples in the dc side.

After this introduction, the mathematical background of the sinusoidal PWM (SPWM) is presented in Section II. The inverter dc side formula is explained in Section II in which the impact of line harmonics on the dc side current is discussed too. Simulation results are provided in Section III. The frequency spectrum of the inverter dc side current is presented and discussed in this section. Conclusions are presented and discussed in Section IV.

\section{SPWM CONTROL AND LINE HARMONICS OF A THREE-PHASE INVERTER}

A three-phase inverter is a voltage source converter device that converts a dc voltage to a desirable threephase voltage with an arbitrary voltage and frequency within the operation limit. There are different ways to generate the voltage; that is how one turns on or off 8 power switches. The SPWM method is one of the widely used schemes in which the command signals are generated by comparison of a high frequency carrier waveform with a reference signal having the desired fundamental frequency [3]. The inverter can be connected to a three-phase load that can be symmetric or asymmetric. Moreover, it can be a four-wire connection or a three-wire connection in which the null current is zero. Depending on the type of load, different harmonics are presented in the line current. The SPWM strategy and major line harmonics of a balanced three-phase threewire load is presented in this section.

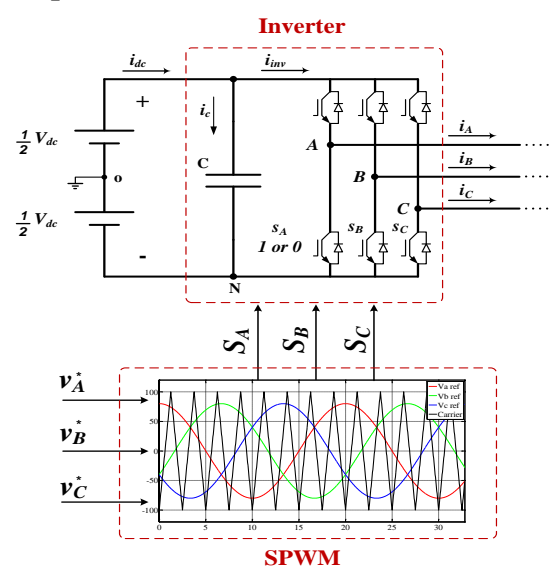

Figure 1. The main diagram of a three-phase SPWM inverter. 
Three-phase Voltages: References and Carrier

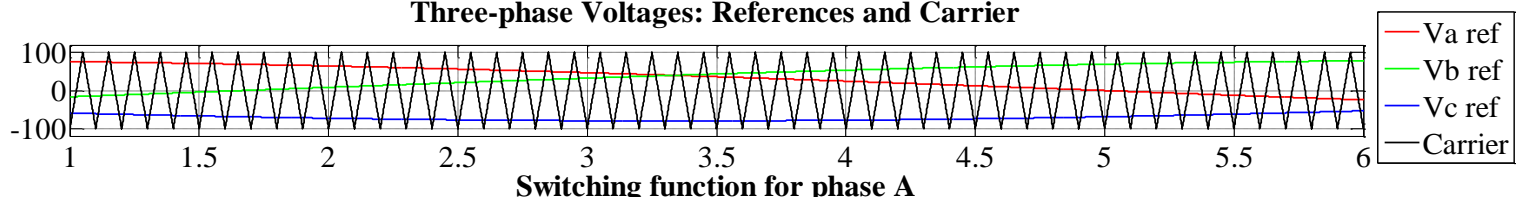

Switching function for phase A
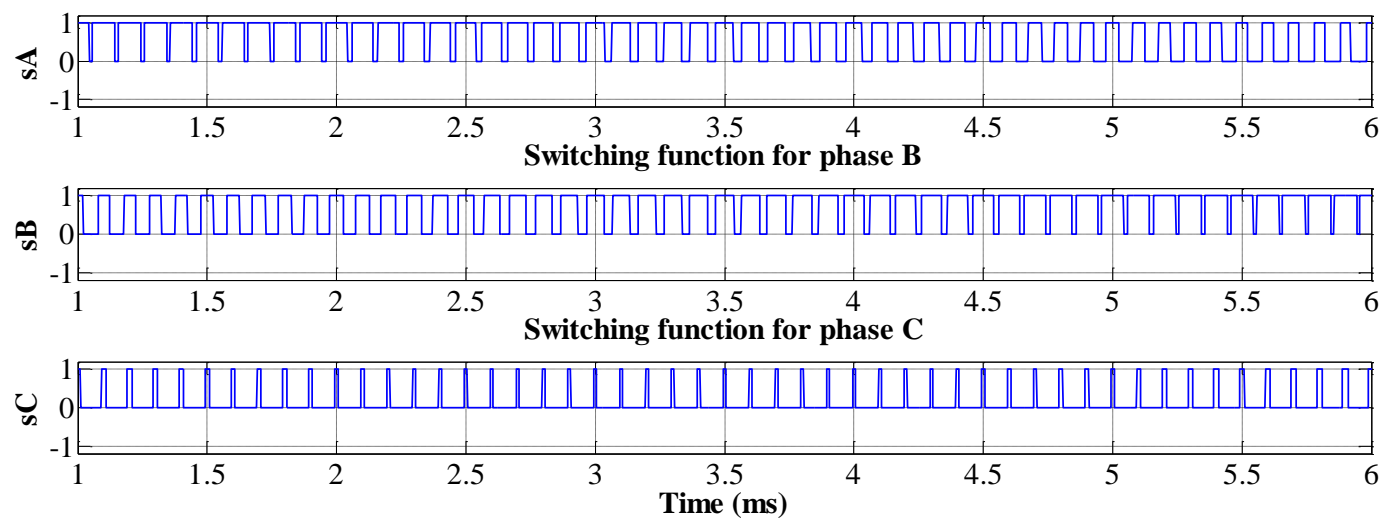

Figure 2. Control of a three-phase inverter using a naturally sampled SPWM: reference signals, carrier waveforms and switching functions.

\section{A. SPWM Control of a Three-Phase Inverter}

The basic diagram of a three-phase SPWM inverter is shown in Fig. 1. The gate command signals are generated by comparison of a high frequency carrier waveform, a high-frequency triangular waveform in this case, with a reference signal with the fundamental frequency. The main dc bus capacitor, $\mathrm{C}$, filters the high frequency components in the $\mathrm{dc}$ side. There are six controlled switches named $\mathrm{A}, \mathrm{B}$ and $\mathrm{C}$ which are in three legs. In each leg, the switches turn on and turn off status is in opposite order; so the top and bottom switches cannot conduct in the same time. The symbols SA, SB and SC are used to describe the status of the switches in each phase, which can be either 1 or 0 . Status 1 indicates the case that the top switch is on and the bottom switch is off and status 0 stands for the vice versa. As can be seen from the figure, the negative dc terminal is marked as $\mathrm{N}$ and the midpoint of the dc source is indicated as 0 . Moreover, the ac side load is not shown in this figure and just the load currents are presented which is sufficient in this context.

It is assumed that the controller is based on a naturally sampled three-phase SPWM schemes with a triangular carrier wave with an angular frequency of $\omega_{c}=2 \pi f_{c}=$ $\frac{2 \pi}{T_{c}}$. The switches' commands are generated by comparison of a sinusoidal reference and the triangular carrier. There are three reference signals with an angular frequency of $\omega_{o}=2 \pi f_{o}=\frac{2 \pi}{T_{o}}$ which are compared with a single carrier waveform to generate three control signals of $S_{A}, S_{B}$ and $S_{C}$.

Assume that the reference voltages are

$$
\begin{gathered}
v_{A o}^{*}=V_{o} \cos \left(\omega_{o} t\right)=\frac{1}{2} V_{d c} M \cos \left(\omega_{o} t\right) \\
v_{B o}^{*}=V_{o} \cos \left(\omega_{o} t-\frac{2 \pi}{3}\right)=\frac{1}{2} V_{d c} M \cos \left(\omega_{o} t-\frac{2 \pi}{3}\right) \\
v_{C o}^{*}=V_{o} \cos \left(\omega_{o} t+\frac{2 \pi}{3}\right)=\frac{1}{2} V_{d c} M \cos \left(\omega_{o} t+\frac{2 \pi}{3}\right)
\end{gathered}
$$

where $V_{o}$ is the peak of output voltage, $V_{d c}$ is the dc source voltage, and $\mathrm{M}$ is the modulation index defined as $M=\frac{2 V_{o}}{V_{d c}}$. Here it is assumed that the value of $M$ is between 0 and 1 as $0 \leq M \leq 1$.

Fig. 2 shows the three-phase reference voltages for the phase $\mathrm{A}, \mathrm{B}$ and $\mathrm{C}$ and the triangular carrier waveform for a few cycles of a SPWM without the zero sequence injection. Moreover, the switching functions SA, SB and $\mathrm{SC}$ are shown in this figure too. As mentioned earlier, the PWM is of the naturally sampled type, in which the control signals are not constant during the carrier period. For a regularly sampled PWM, the control signals are constant during each carrier period or for half a period [3]

The output phase potentials with respect to point $\mathrm{N}$ can be written as [3].

$$
\begin{gathered}
v_{A N}= \\
\frac{1}{2} V_{d c}+\frac{1}{2} V_{d c} M \cos \left(\omega_{o} t\right)+ \\
\frac{2 V_{d c}}{\pi} \sum_{m=1}^{\infty} \sum_{n=-\infty}^{n=\infty} \frac{1}{m} J_{n}\left(m \frac{\pi}{2} M\right) \sin ((m+ \\
\left.n) \frac{\pi}{2}\right) \cos \left(m \omega_{c} t+n \omega_{o} t\right) \\
v_{B N}= \\
\frac{1}{2} V_{d c}+\frac{1}{2} V_{d c} M \cos \left(\omega_{o} t-\frac{2 \pi}{3}\right)+ \\
\frac{2 V_{d c}}{\pi} \sum_{m=1}^{\infty} \sum_{n=-\infty}^{n=\infty} \frac{1}{m} J_{n}\left(m \frac{\pi}{2} M\right) \sin ((m+ \\
\left.n) \frac{\pi}{2}\right) \cos \left(m \omega_{c} t+n\left(\omega_{o} t-\frac{2 \pi}{3}\right)\right) \\
\frac{1}{2} V_{d c}+\frac{1}{2} V_{d c} M \cos \left(\omega_{o} t+\frac{2 \pi}{3}\right)+ \\
\frac{2 V_{d c}}{\pi} \sum_{m=1}^{\infty} \sum_{n=-\infty}^{n=\infty} \frac{1}{m} J_{n}\left(m \frac{\pi}{2} M\right) \sin ((m+ \\
\left.n) \frac{\pi}{2}\right) \cos \left(m \omega_{c} t+n\left(\omega_{o} t+\frac{2 \pi}{3}\right)\right)
\end{gathered}
$$

where $J_{\alpha}(x)$ is the Bessel function of the first kind. In each of the above equations, there is a dc components and a fundamental component with the angular frequency of $\omega_{o}$. The rest of the components include undesirable high 
frequency components that are around the carrier frequency and its multiples.

\section{B. AC Line Harmonics of a Three-Phase Three-Wire Inverter}

A three-phase load connected to a three-phase inverter can include harmonics in addition to the dc component for each phase. Some harmonics cannot exist in the ac line of a three-phase three-wire symmetric load due to the symmetry and zero-null current; there are no even and triplen harmonics in the ac side [5]. Hence, the existing harmonics are $5^{\text {th }}, 7^{\text {th }}, 11^{\text {th }}, 13^{\text {th }}$ and so on. The $5^{\text {th }}$ and $7^{\text {th }}$ harmonics are major components and higher orders have lower significance [5]. At this work only $5^{\text {th }}$ and $7^{\text {th }}$ harmonics are considered and higher orders are neglected for the sake of simplicity in the analytical formulation.

Assume that the inverter ac line currents are

$$
\begin{gathered}
i_{A}=I_{1} \cos \left(\omega_{o} t+\emptyset_{1}\right)+I_{5} \cos \left(5 \omega_{o} t+\emptyset_{5}\right)+ \\
I_{7} \cos \left(7 \omega_{o} t+\emptyset_{7}\right) \\
i_{B}=I_{1} \cos \left(\omega_{o} t-\frac{2 \pi}{3}+\emptyset_{1}\right)+I_{5} \cos \left(5\left(\omega_{o} t-\frac{2 \pi}{3}\right)+\right. \\
\left.\emptyset_{5}\right)+I_{7} \cos \left(7\left(\omega_{o} t-\frac{2 \pi}{3}\right)+\emptyset_{7}\right) \\
i_{C}=I_{1} \cos \left(\omega_{o} t+\frac{2 \pi}{3}+\emptyset_{1}\right)+I_{5} \cos \left(5\left(\omega_{o} t+\frac{2 \pi}{3}\right)+\right. \\
\left.\emptyset_{5}\right)+I_{7} \cos \left(7\left(\omega_{o} t+\frac{2 \pi}{3}\right)+\emptyset_{7}\right)
\end{gathered}
$$

where $\omega_{o}$ is the angular frequency of the current; symbols $\mathrm{I}_{1}, \mathrm{I}_{5}, \mathrm{I}_{7}, \emptyset_{1}, \emptyset_{5}$, and $\emptyset_{7}$ are the magnitude of current and phase angles of the $1^{\text {th }}, 5^{\text {th }}$ and $7^{\text {th }}$ harmonics, respectively.

Fig. 3 shows the three-phase line currents with higher order harmonics. The fundamental frequency is $50 \mathrm{~Hz}$, and there are 5th and 7th harmonic components. For the phase A, each harmonic component is shown separately in the bottom section of the figure.
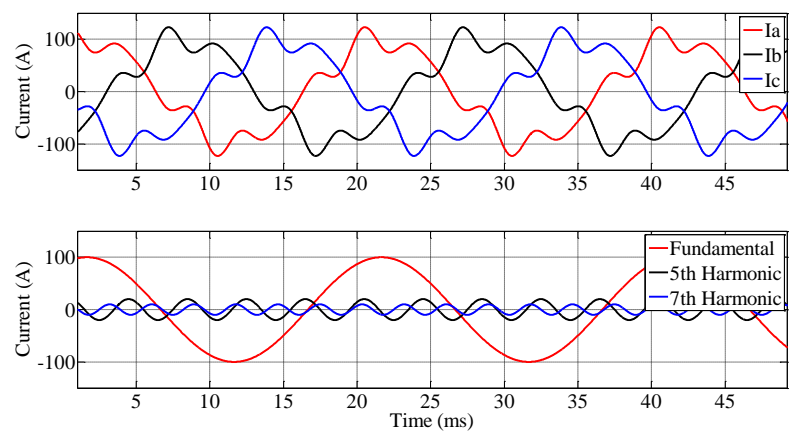

Figure 3. Three-Phase ac line currents with the 5th and 7th harmonics: three-phase currents (top) and the current of the phase A decomposed to its harmonics (bottom).

By using the switching functions, the inverter dc side current, $\mathrm{i}_{\text {inv }}$, can be described as [6]

$$
i_{\text {inv }}=S_{A} i_{A}+S_{B} i_{B}+S_{C} i_{C}
$$

where $i_{A}, i_{B}$ and $i_{C}$ are inverter ac line currents. To find out the analytical formula for the switching functions $\mathrm{S}_{\mathrm{A}}, \mathrm{S}_{\mathrm{B}}$ and $\mathrm{S}_{\mathrm{C}}$, it is possible to set $V_{d c}=1$ in (4-6). That is the Fourier series of the transistor switching functions. The values of the switching functions are 0 or 1 ; here they are approximated by their Fourier series. Recalling the equations, there are the dc component, the fundamental component and the components around the carrier frequency or its multiple frequencies. If the high frequency components are ignored, it is possible to investigate the low frequency harmonics resulting from current harmonics. The low frequency is much less than the carrier frequency in this case. Using (4-6) and $V_{d c}=1$, the switching functions are

$$
\begin{aligned}
& S_{A}=\frac{1}{2}+\frac{1}{2} M \cos \left(\omega_{o} t\right)\left(\omega_{o} t\right)+H O T \\
& S_{B}=\frac{1}{2}+\frac{1}{2} M \cos \left(\omega_{o} t-\frac{2 \pi}{3}\right)+H O T \\
& S_{A}=\frac{1}{2}+\frac{1}{2} M \cos \left(\omega_{o} t+\frac{2 \pi}{3}\right)+H O T
\end{aligned}
$$

where HOT stands for higher order terms.

For a SPWM inverter with a pure sinusoidal line currents, the inverter dc side current, $i_{\text {inv }}$, is [7]

$$
\begin{gathered}
i_{i n v}=\frac{3}{4} M I_{o} \cos \emptyset+I_{o} \frac{3}{\pi}\{\ldots+ \\
\sqrt{J_{2}^{2}\left(\frac{\pi}{2} M\right)+J_{4}^{2}\left(\frac{\pi}{2} M\right)-2 J_{2}\left(\frac{\pi}{2} M\right) J_{4}\left(\frac{\pi}{2} M\right) \cos 2 \emptyset} \cos \left(\omega_{c} t\right. \\
\left.-3 \omega_{o} t+\emptyset_{11}\right) \\
+\sqrt{J_{2}^{2}\left(\frac{\pi}{2} M\right)+J_{4}^{2}\left(\frac{\pi}{2} M\right)-2 J_{2}\left(\frac{\pi}{2} M\right) J_{4}\left(\frac{\pi}{2} M\right) \cos 2 \emptyset} \cos \left(\omega_{c} t\right. \\
\left.+3 \omega_{o} t+\emptyset_{12}\right)+\cdots \\
\left.\ldots-\frac{2}{2} J_{1}\left(2 \frac{\pi}{2} M\right) \cos \varphi \cos 2 \omega_{c} t+\ldots\right\} .
\end{gathered}
$$

The high-frequency harmonics can be detected from (14). It is desirable to have an equivalent circuit of the inverter and load from the de terminal to study different topics at the system level (e.g. stability) [8], [9]. A simple model is to replace the unit by a constant current source.

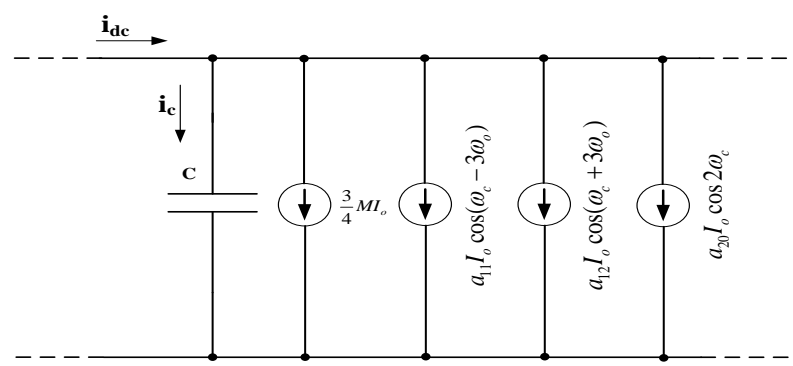

Figure 4. The harmonic model of a three-phase SPWM inverter with a pure sinusoidal line current towards the dc bus.

This model cannot be used to explain high frequency ripples in the DC-bus. Based on the developed equations of the inverter system at the DC-side, a more accurate equivalent circuit can be used. Fig. 4 shows the proposed equivalent circuit where coefficients $\mathrm{a}_{11}, \mathrm{a}_{12}$ and $\mathrm{a}_{20}$ are defined by (14). The major harmonics are around $\omega_{c}$ and $2 \omega_{c}$.

For the case that there are $5^{\text {th }}$ and $7^{\text {th }}$ harmonics on the line current, (14) is modified to the following equation, (15), by using (7-13). So, the inverter dc side current for a line current with higher order harmonics is

$$
\begin{aligned}
\mathrm{i}_{\mathrm{inv}}= & \frac{3}{4} M I_{1} \cos \phi_{1}+\frac{3}{4} M I_{5} \cos \left(6 \omega_{o} t+\phi_{5}\right) \\
& +\frac{3}{4} M I_{7} \cos \left(6 \omega_{o} t+\phi_{7}\right)+H O T
\end{aligned}
$$


In addition to higher order components, there are three components in the inverter $\mathrm{dc}$ side current; one $\mathrm{dc}$ component and two harmonic components with an order of 6 . As can be seen from this equation, for a pure sinusoidal three-phase line current, there will be just a dc component that is responsible for the power transfer. In addition, there are two other ac components with a harmonic order of 6 that are the impact of 5 th and $7^{\text {th }}$ harmonics of the ac line.

The higher order harmonics around the carrier frequency or its multiple frequencies can easily be filtered by the main capacitor, C. So, they are not considered here. However, the low frequency harmonic with an order of 6 is very severe in the system that needs a large filter to be smoothed. As mentioned earlier, this undesirable harmonic is the impact of $5^{\text {th }}$ and $7^{\text {th }}$ harmonics in the ac line currents.
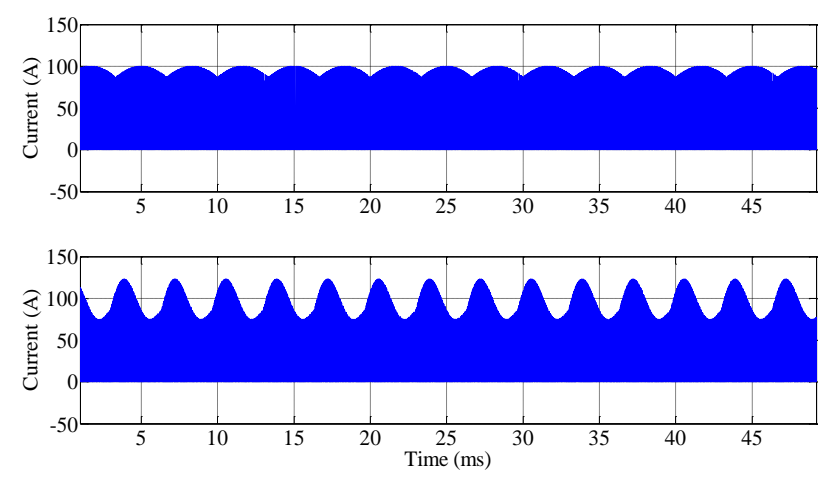

Figure 5. The inverter dc side current in time domain for two cases: fundamental component and fundamental plus harmonics.

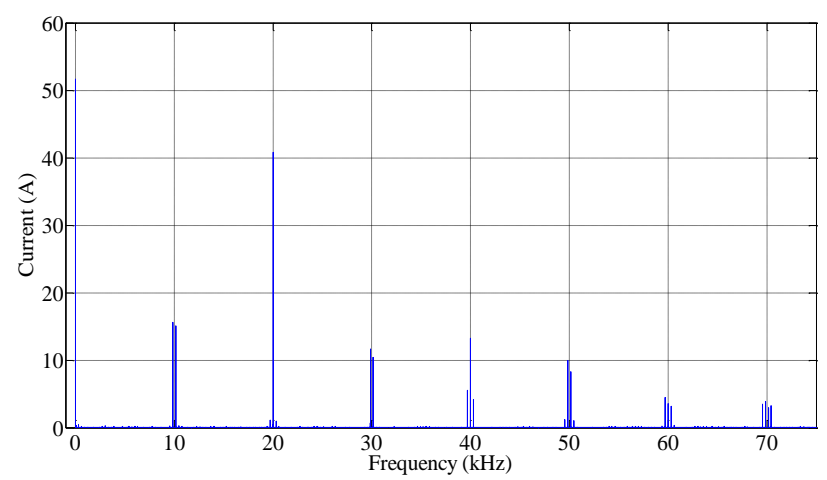

Figure 6. The frequency spectrum of the inverter dc side current with a fundamental sinusoidal line current without higher order harmonics.

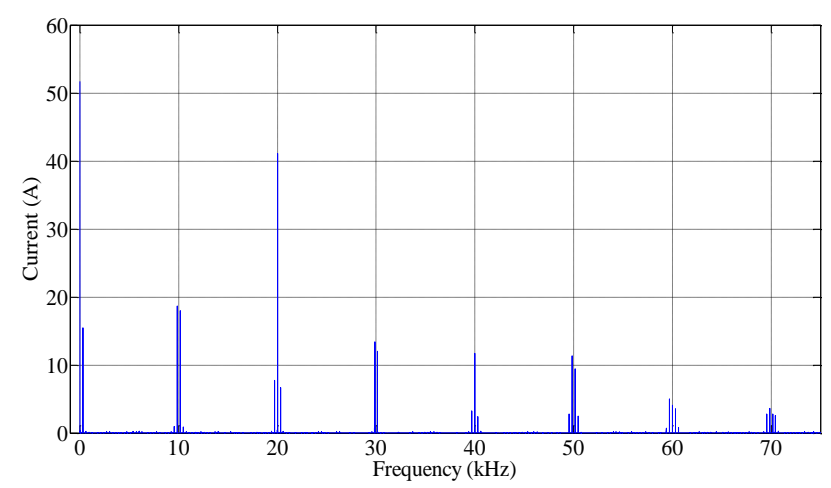

Figure 7. The frequency spectrum of the inverter dc side current with a fundamental sinusoidal line current with 5 th and 7 th order harmonics.

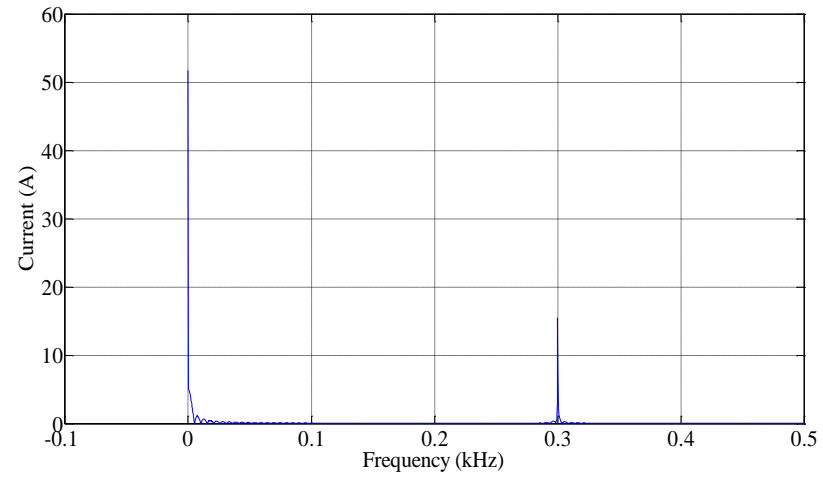

Figure 8. The frequency spectrum of the inverter dc side current with a fundamental sinusoidal line current with 5 th and 7 th order harmonics: low frequency region.

\section{SimUlation RESUltS AND DisCUSSIONS}

The inverter dc side current is simulated for different harmonics and power factors to evaluate the impact of ac line harmonics on the dc side. Fig. 5 depicts the inverter dc side current for a SPWM inverter with a line currents presented in Fig. 3. In addition, the inverter dc side current is shown for the case when the $5^{\text {th }}$ and $7^{\text {th }}$ harmonics are set to zero. As one can conclude from the figure, adding higher order harmonics on the ac line will increase the dc side current fluctuation. However, to be able to quantify the impact, a frequency spectral analysis has been performed where the results are shown in Fig. 6, Fig. 7 and Fig. 8. Fig. 6 shows the frequency spectrum for a pure sinusoidal line currents without higher order harmonics. The spectrum is the same as predicted in (14). Fig. 8 shows the spectrum of the inverter dc side current when there are $5^{\text {th }}$ and $7^{\text {th }}$ harmonics in the line current according to Fig. 3. A low frequency harmonic is recognizable in the figure. This is according to the derived analytical equation (15). The switching frequency is $10 \mathrm{kHz}$ and the fundamental frequency is $50 \mathrm{~Hz}$ in this case.

The resulting low frequency harmonic with an order of 6 is very difficult to mitigate. A large filter capacitor is needed to filter out this low frequency component which can be harmful for the battery. It is recommended that for the ac motor, the designer enhances the design towards a lower $5^{\text {th }}$ and $7^{\text {th }}$ harmonics since it has a considerable impact on the dc side battery current.

\section{CONCLUSION}

The dc bus quality is an important concern for systems with multiple converters connecting to a common dc bus. The impact of higher order line harmonics of a threephase SPWM inverter on the dc side current is investigated in this paper. For a three-phase, three-wire system connected to a balanced load, it has been shown that the $5^{\text {th }}$ and $7^{\text {th }}$ harmonics in the line current will result in a $6^{\text {th }}$ harmonic current in the dc side. An analytical formula is presented to quantify this harmonic value. Simulation results are presented to verify the analytical formulation. 


\section{REFERENCES}

[1] B. K. Bose, Modern Power Electronics and AC Drives, India: Prentice Hall, 2005.

[2] H. Wen, W. Xiao, H. Li, and W. Wen, "Analysis and minimisation of DC bus surge voltage for electric vehicle applications," Electrical Systems in Transportation, IET, vol. 2, no. 2, pp. 68-76, Jun. 2012.

[3] Holmes and T. Lipo, Pulse Width Modulation for Power Converts: Principles and Practice, Wiley-IEEE Press, 2003.

[4] Wen Huiqing, Xiao Weidong, Wen Xuhui, and P. Armstrong, "Analysis and evaluation of DC-Link capacitors for high-powerdensity electric vehicle drive systems," IEEE Transactions on Vehicular Technology, vol. 61, no. 7, pp. 2950-2964, Sep. 2012.

[5] R. W. Erickson and D. Maksimovic, Fundamentals of Power Electronics, 2nd ed. Springer, 2001.

[6] P. A. Dahono, A. Purwadi, and T. Kataoka, "A new approach for harmonic analysis of three-phase current-type PWM converters," in Proc. Thirty-Second IAS Annual Meeting, IAS 997., Conference Record of the 1997 IEEE Industry Applications Conference, Oct. 1997, pp. 1487-1495.

[7] S. Haghbin and T. Thiringer, "Harmonic modeling of a vehicle traction circuit towards the dc bus," in Proc. International Power Electronics Conference, Hiroshima, 2014.

[8] Boroyevich, I. Cvetkovic, D. Dong, R. Burgos, W. Fei, and F. Lee "Future electronic power distribution systems a contemplative view," in Proc. 12th International Conference on Optimization of Electrical and Electronic Equipment (OPTIM), May 2010, pp. 1369-1380.

[9] P. McGrath and D. G. Holmes, "A general analytical method for calculating inverter DC-link current harmonics," IEEE Transactions on Industry Applications, vol. 45, no. 5, pp. 1851$1859,2009$.

Saeid Haghbin received his Master degree in electrical engineering from Sharif University of Technology, Iran, in 2003. During 2003-2007 he was working in industry mainly on power electronic systems and automation. He received his PhD degree in Electric Power Engineering in 2013 from Chalmers University of Technology, Sweden. At the present time he is a postdoctoral fellow at Chalmers University of Technology. His main research interests are power electronics, drive systems and related signal processing.

Torbjörn Thiringer works at Chalmers university of Technology, in Gothenburg Sweden, as a professor in applied power electronics. He took his M.Sc and Ph.D at Chalmers University of technology in 1989 and 1996 respectively. His areas of interest include the modeling, control and grid integration of wind energy converters into power grids as well as power electronics and drives for other types of applications, such as electrified vehicles, buildings and industrial applications. 